\title{
MicroRNA-29a inhibits cell proliferation and arrests cell cycle by modulating p16 methylation in cervical cancer
}

\author{
ANJIN WANG ${ }^{1}$, QIYING XU ${ }^{2}$, RENGAOWA SHA ${ }^{2}$, TONGHUI BAO ${ }^{2}$, XIAOLI XI $^{3}$ and GUILAN GUO ${ }^{2}$ \\ ${ }^{1}$ School of Basic Medical Sciences, Wuhan University, Wuhan, Hubei 430072; ${ }^{2}$ Department of Gynecology, \\ Affiliated Hospital of Qinghai University, Xining, Qinghai 810100; ${ }^{3}$ Department of Medicine, \\ Qinghai University, Xining, Qinghai 810016, P.R. China
}

Received May 29, 2020; Accepted December 14, 2020

DOI: $10.3892 / \mathrm{ol} .2021 .12533$

\begin{abstract}
Cervical cancer is the second most common gynecological malignancy. Accumulating evidence has suggested that microRNAs (miRNAs) are involved in the occurrence and development of cervical cancer. The present study aimed to investigate the function and underlying molecular mechanism of microRNA (miRNA/miR)-29a in cervical cancer. Reverse transcription-quantitative PCR and methylation-specific PCR were used to examine the expression of miR-29a and methylated status of p16 promoter, respectively. Cell Counting Kit- 8 analysis and flow cytometry were performed to evaluate cell viability and cycle, respectively. Dual-luciferase reporter assay was performed to verify the interaction between miR-29a and its targets. Western blot analysis was performed to detect the protein levels of DNA methyltransferases (DNMT)3A and DNMT3B. The results demonstrated that miR-29a expression was downregulated in cervical cancer tissues and cells, and negatively correlated with p16 promoter hypermethylation. Furthermore, cell experiments confirmed that miR-29a suppressed cell proliferation and induced cell cycle arrest in HeLa and C-33A cells Mechanically, miR-29a restored normal methylation pattern of the p16 gene by sponging DNMT3A and DNMT3B. Taken together, the results of the present study demonstrated the epigenetic regulation of tumor suppressor p16 by miR-29a as a unique mechanism, thus providing a rationale for the development of miRNA-based strategies in the treatment of cervical cancer.
\end{abstract}

Correspondence to: Dr Guilan Guo, Department of Gynecology, Affiliated Hospital of Qinghai University, 29 Tongren Road, Xining, Qinghai 810100, P.R. China

E-mail: 09717513976ggl@163.com

Abbreviations: miRNA/miR, microRNA; DNMTs, DNA methyltransferases

Key words: microRNA 29a, cervical cancer, methylation, proliferation, cell cycle

\section{Introduction}

Cervical cancer is the second most common gynecological malignancy, with an estimated 570,000 cases and 311,000 deaths in 2018 worldwide (1). Although several studies have revealed that the human papillomavirus is the most important cause of cervical cancer, other factors are required for malignant transformation of cervical cell (2). Genetic factors are also involved in the development of cervical cancer (3). Thus, innovative biomarkers and related molecular mechanisms are essential for the diagnosis, prognosis and treatment of cervical cancer.

DNA methylation is one of the predominant epigenetic modifications in mammals, which performs a critical function in regulating gene expression (4). Aberrant DNA methylation, particularly methylation of $\mathrm{CpG}$ islands in gene promoter regions, often occurs in different types of cancer, incuding cervical cancer and is an early event of malignant transformation $(5,6)$. P16 is a common studied tumor suppressor gene (7). The promoter regions of p16 are often methylated, which decreases the levels of p16 in cervical cancer (8). Previous studies have demonstrated that p16 promoter methylation is closely associated with the development and progression of cervical cancer, so it is considered a potential diagnostic and therapeutic target $(9,10)$. The changes involved in DNA methylation are controlled by DNA methyltransferases (DNMTs) (11). A total of three catalytically active DNMTs (DNMT1, DNMT3A and DNMT3B) have been identified in mammals (4). DNMT1 maintains methylation pattern, while DNMT3A and DNMT3B are responsible for de novo DNA methylation (12). Previous studies have reported elevated levels of DNMT1, DNMT3A and DNMT3B in various tumors, including hepatic, prostate, colorectal and breast cancers (13-16). Recently, high DNMT1 protein expression was reported in cervical cancer, and is associated with poor survival outcome (17). Inhibition of DNMTs can reactivate the expression of methylation-silenced tumor suppressor genes in human cervical cancer cells (18-20).

MicroRNAs (miRNAs/miRs) are a class of short (20-24 nucleotides) non-coding RNA molecules that negatively regulate gene expression by translational inhibition or destabilization of targets through binding to the 3'-untranslated region (UTR) of mRNAs (21). miRNAs play 
important roles in several biological processes, such as cell proliferation, apoptosis, differentiation and cell cycle (22). Thus, abnormal expression or dysfunction of miRNAs are associated with the development of diseases, including cancer (23). miR-29a is a tumor suppressor gene that can inhibit the malignant proliferation, invasion and metastasis of several human cancer cells (24-26). Furthermore, miR-29a suppresses cell proliferation by targeting SIRT1 in cervical and hepatocellular carcinomas $(27,28)$. miR-29a also inhibits cell proliferation, migration and invasion by directly targeting CDC42 in cervical cancer, osteosarcoma, gliomas and breast cancer (29-32). In addition, miR-29a inhibits cancer cell migration and invasion by targeting HSP47 in cervical squamous cell carcinoma (33). Increasing evidence suggests that miR-29a regulates DNA methylation with the suppression of DNMTs in lung cancer (34), hepatocellular carcinoma $(35,36)$, Burkitt lymphoma cells (37) and T-cell acute lymphoblastic leukemia (38).

Thus, the present study aimed to investigate the role of miR-29a and whether miR-29a regulates the methylated status of p16 promoter by modulation of DNMT3s in cervical cancer.

\section{Materials and methods}

Tissue samples. In the present study, 40 patients who underwent cervical cancer surgery at the Affiliated Hospital of Qinghai University between January 2017 and December 2018 were recruited. All participants were female, with a median age of 55 years (age range, 32-68 years). Cervical cancer tissues and paired adjacent normal tissues were collected in surgery, and the distance between adjacent normal and cancer tissue boundary was $\sim 1-2 \mathrm{~cm}$. The present study was approved by the Ethics Committee of the Affiliated Hospital of Qinghai University (Xining, China; approval no. SL-2018016) and written informed consent was provided by all patients prior to the study start. Tissue samples were obtained during surgical resection and immediately snap-frozen in liquid nitrogen, and stored at $-80^{\circ} \mathrm{C}$ until subsequent experimentation. Diagnosis was independently confirmed via two pathologists from the Affiliated Hospital of Qinghai University.

Cell culture. The human cervical cancer cell lines, HeLa and C-33A, were purchased from The Cell Bank of the Chinese Academy of Sciences, while the ectocervical epithelial cell line, ECT1/E6E7, was purchased from the American Type Culture Collection. The cervical cell lines were maintained in DMEM supplemented with $10 \%$ fetal bovine serum (both purchased from Gibco; Thermo Fisher Scientific, Inc.), $100 \mathrm{U} / \mathrm{ml}$ penicillin and $100 \mu \mathrm{g} / \mathrm{ml}$ streptomycin (Invitrogen; Thermo Fisher Scientific, Inc.), at $37^{\circ} \mathrm{C}$ with $5 \% \mathrm{CO}_{2}$.

Reverse transcription-quantitative $(R T-q) P C R$. Total RNA was extracted from cervical cancer cells and tissues using TRIzol ${ }^{\circledR}$ reagent (Invitrogen, Thermo Fisher Scientific, Inc.), according to the manufacturer's protocol. RT was performed using PrimeScript 1st Strand cDNA synthesis kit (cat. no. 6110A; Takara Bio, Inc.) at $37^{\circ} \mathrm{C}$ for $15 \mathrm{~min}$. qPCR was subsequently performed using the SYBR Green PCR Master Mix (Takara Bio, Inc.). The following conditions were used for all RT-PCR assays: $95^{\circ} \mathrm{C}$ for $30 \mathrm{sec}$, followed by 40 cycles of $95^{\circ} \mathrm{C}$ for $15 \mathrm{sec}$ and $60^{\circ} \mathrm{C}$ for $35 \mathrm{sec}$. After the PCR run, a melting curve analysis was performed at a melting rate of $0.1^{\circ} \mathrm{C} / \mathrm{sec}$, and data were collected every $0.23^{\circ} \mathrm{C}$ from $6-95^{\circ} \mathrm{C}$ (LineGene9600 version 1, Bioer Technology). Relative expression levels were calculated using the $2^{-\Delta \Delta \mathrm{Cq}}$ method (39) and all experiments were performed in triplicate. miR-29a expression was assessed via the stem-loop RT primer assay and U6 was used as the internal control. DNMT3A and DNMT3B mRNA expression was standardized to control values of GAPDH. The primers sequences used for qPCR are listed in Table I.

Methylation-specific PCR (MSP). Genomic DNA was bisulphite converted using the EZ DNA Methylation Gold bisulphite conversion kit (cat. no. D5008, Zymo Research Corp. Irvine, CA) and diluted to a final concentration of $20 \mathrm{ng} / \mu \mathrm{l}$. MS-PCR primers [targeting methylated sequence (M) and unmethylated sequence (U)] were designed using MethPrimer 2.0 to span the $\mathrm{CpG}$ island of the p16 promoter region. The following thermocycling conditions were used: Initial denaturation at $95^{\circ} \mathrm{C}$ for $2 \mathrm{~min}$, followed by 35 cycles of denaturation at $94^{\circ} \mathrm{C}$ for $30 \mathrm{sec}$, annealing at $55^{\circ} \mathrm{C}$ for $30 \mathrm{sec}$, extension at $72^{\circ} \mathrm{C}$ for $60 \mathrm{sec}$ and a final extension at $72^{\circ} \mathrm{C}$ for $4 \mathrm{~min}$. The methylation-specific primers for $\mathrm{p} 16$ are presented in Table I. The PCR products were stained with ethidium bromide for $2 \mathrm{~min}$ at $37^{\circ} \mathrm{C}$, analyzed on $2 \%$ agarose gels and subsequently visualized via UV illumination. The presence of specific bands in (M) or both $(\mathrm{M})$ and $(\mathrm{U})$ were considered positive for methylation. However, the presence of specific bands only observed in (U) but not in (M) were considered unmethylated.

Western blotting. Total protein was extracted from cervical cancer cells using RIPA lysis buffer (Sigma-Aldrich; Merck $\mathrm{KGaA}$ ) and qualified using the BCA detecting kit (cat. no. P0006, Beyotime Institute of Biotechnology), according to the manufacturer's instructions. A total of $50 \mu \mathrm{g}$ protein/lane was separated by $10 \%$ SDS-PAGE, transferred onto PVDF membranes (EMD Millipore) and blocked with $5 \%$ dry milk blocking buffer for $2 \mathrm{~h}$ at room temperature. The membranes were incubated with primary antibodies against DNMT3A (1:1,000; cat. no. ab188470; Abcam), DNMT3B (1:1,000; cat. no. ab79822; Abcam) and tubulin (1:2,000; cat. no. ab7291; Abcam) overnight at $4^{\circ} \mathrm{C}$. Following the primary incubation, membranes were incubated with HRP-conjugated goat anti-rabbit $\operatorname{lgG}(\mathrm{H}+\mathrm{L})(1: 2,000$; cat. no. ab205718; Abcam) at room temperature for $40 \mathrm{~min}$. Protein bands were visualized using an enhanced chemiluminescence detection system (Pierce; Thermo Fisher Scientific, Inc.) and intensities of bands were quantified using Image $\mathrm{Lab}^{\mathrm{TM}}$ software (Bio-Rad Laboratories, Inc.).

Cell transfection. miR-29a mimics (miR-29a) and scrambled miRNA (Scrambled), siRNA for DNMT3A (si-DNMT3A), siRNA for DNMT3B (si-DNMT3B) and negative control (siRNA-NC) were purchased from Shanghai GenePharma Co., Ltd., and the sequences are presented in Table I. HeLa and C-33A cells were seeded into 6-well plates at a density of $2 \times 10^{5}$ cells/well and cultured at $37^{\circ} \mathrm{C}$ for $24 \mathrm{~h}$, prior to transfection using the Lipofectamine ${ }^{\circledR} 2000$ kit (cat. no. 11668027; Invitrogen, Thermo Fisher Scientific, Inc.) at $37^{\circ} \mathrm{C}$ for $48 \mathrm{~h}$, according to the manufacturer's protocol. 
Table I. Primer sequences.

\begin{tabular}{|c|c|}
\hline Gene & Sequence $\left(5^{\prime}-3^{\prime}\right)$ \\
\hline miR-29a & $\begin{array}{l}\text { F: ACACTCCAGCTGGGTTTGGAGTCT } \\
\text { R: CTCAACTGGTGTCGTGGA }\end{array}$ \\
\hline U6 & $\begin{array}{l}\text { F: CTCGCTTCGGCAGCACA } \\
\text { R: AACGCTTCACGAATTTGCGT }\end{array}$ \\
\hline DNMT3A & $\begin{array}{l}\text { F: GCTGCACCTGGCCTTATG } \\
\text { R: GGCTTTCTTCTCAGCCGTATC }\end{array}$ \\
\hline DNMT3B & $\begin{array}{l}\text { F: CCAATCCTGGAGGCTATCCG } \\
\text { R: CCGTCTCAGGGACTGTGTGT }\end{array}$ \\
\hline GAPDH & $\begin{array}{l}\text { F: ATGACATCAAGAAGGTGGT } \\
\text { R: GCGTCAAAGGTGGAGGA }\end{array}$ \\
\hline $\mathrm{P} 16$ [U] & $\begin{array}{l}\text { TTATTAGAGGGTGGGGTGGATTGT } \\
\text { CAACCCCAAACCACAACCATAA }\end{array}$ \\
\hline $\mathrm{P} 16[\mathrm{M}]$ & $\begin{array}{l}\text { TTATTAGAGGGTGGGGCGGATCGC } \\
\text { GACCCCGAACCGCGACCGTA }\end{array}$ \\
\hline $\begin{array}{l}\text { DNMT3A siRNA } \\
\text { DNMT3B siRNA } \\
\text { siRNA-NC } \\
\text { miR-29a mimics }\end{array}$ & $\begin{array}{l}\text { GCGUCACACAGAAGCAUAUTT } \\
\text { UUGUUGUUGGCAACAUCUGAA } \\
\text { CAGAUGUUGCCAACAACAAGA } \\
\text { ACCCCTTAGAGGATGACTGATTTCTTTTGGTGTTCAG } \\
\text { AGTCAATAGAATTTTCTAGCACCA } \\
\text { TCTGAAATCGGTTATAATGATTGGGGA }\end{array}$ \\
\hline
\end{tabular}

miR, microRNA; DNMT, DNA methyltransferase; si, small interfering; NC, negative control; F, forward; R, reverse.

The final concentrations of miR-29a mimics and siRNAs were $50 \mathrm{nM}$ and $80 \mathrm{nM}$, respectively. Cells were harvested $24 \mathrm{~h}$ post-transfection.

Colony formation assay. Hela and C-33A cells were seeded into 6 -well plates, incubated at $37^{\circ} \mathrm{C}$ for 14 days and fixed with $4 \%$ paraformaldehyde for $30 \mathrm{~min}$ at room temperature. Cells were subsequently stained with $0.1 \%$ crystal violet for $2 \mathrm{~h}$ at room temperature. Colonies ( $>50$ cells) were observed under a light microscope (magnification, x100). Colony forming efficiency $=$ number of colonies/number of seeded cells.

Cell cycle analysis. Transfected cells were digested with trypsin and fixed with $70 \%$ ice-cold ethanol overnight at $-20^{\circ} \mathrm{C}$. Cells were subsequently stained with propidium iodide $(50 \mu \mathrm{g} / \mathrm{ml})$ and RNAse $\mathrm{A}(0.1 \mathrm{mg} / \mathrm{ml})$ for $30 \mathrm{~min}$ at $37^{\circ} \mathrm{C}$ (both purchased from Sigma-Aldrich; Merck $\mathrm{KGaA}$ ), and analyzed using the FACS Calibur flow cytometer (BD Biosciences). All experiments were performed in triplicate.

miRNA target prediction. Potential miR-29a binding sites in the 3'-UTR regions of DNMT3A and DNMT3B mRNA were predicted using the TargetScanHuman 7.2 database (www. targetscan.org). Position 862-868 for DNMT3A and position 1206-1213 for DNMT3B were identified as putative conserved binding sites for miR-29a.

Dual-luciferase reporter assay. The 3'-UTR regions of DNMT3A and DNMT3B mRNA harboring the predicted
miR-29a binding sites [wild-type (wt)-DNMT3A and wt-DNMT3B] or the corresponding mutants [(mut)-DNAMT3A and mut-DNMT3B] were synthesized by Beijing Genomics Institute (https://www.genomics.cn) and subsequently inserted into the pmiRGLO vector (Promega Corporation). HeLa and C-33A cells were transfected with wt-DNMT3A or mut-DNAMT3A, as well as wt-DNMT3B or mut-DNMT3B, followed by transfection with miR-29a mimics or scrambled miRNA using the Lipofectamine ${ }^{\circledR} 2000$ kit (cat. no. 11668027; Invitrogen, Thermo Fisher Scientific, Inc.) at $37^{\circ} \mathrm{C}$ for $48 \mathrm{~h}$. Finally, luciferase activities were detected using a dual-luciferase reporter assay system (Promega Corporation), according to the manufacturer's protocol. The luciferase activity was expressed as fold change compared with the non-treated controls, both as normalized Firefly/Renilla readouts and single luciferase read-outs.

LinkedOmics database. The LinkedOmics database (http://www.linkedomics.org) contains multi-omics data and clinical data for 32 cancer types and a total of 11,158 patients from The Cancer Genome Atlas (TCGA) project (40). LinkedOmics has three data analysis modules: LinkFinder, LinkCompare and LinkInterpreter. The LinkFinder module was used to calculate the association between miR-29a expression and DNMT3A or DNMT3B mRNA expression, and association between p16 expression and DNMT3A or DNMT3B mRNA expression in the TCGA cervical and endocervical cancers (CESC) cohort $(n=304)$, using Pearson's correlation coefficient. 
A

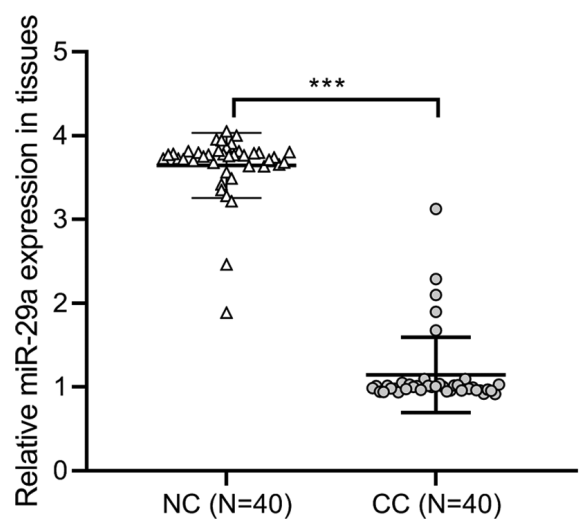

C

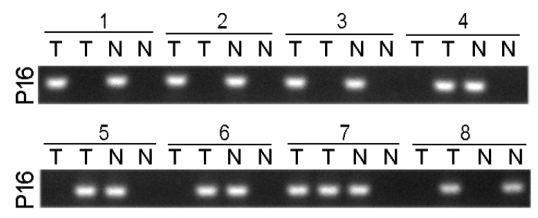

D

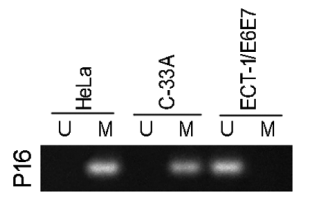

B

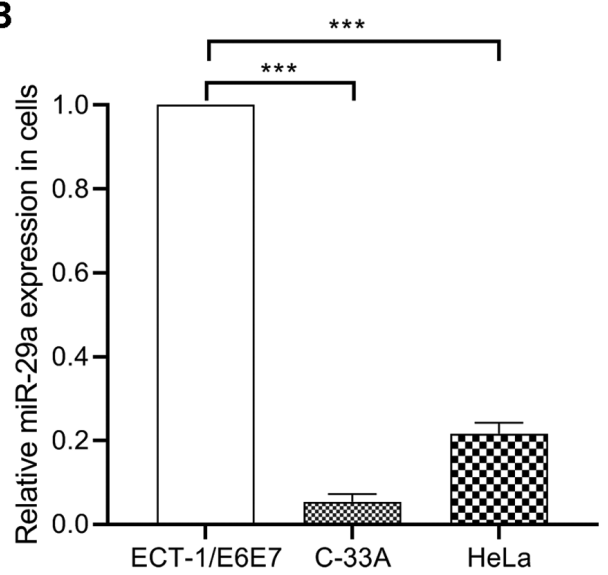

\begin{tabular}{lccc}
\hline & Methylation & Unmethylation & Total \\
\hline Cervical cancer & $25(62.5 \%)$ & $15(37.5 \%)$ & $40(100.0 \%)$ \\
Normal control & $6(15.0 \%)$ & $34(75.0 \%)$ & $40(100.0 \%)$ \\
\hline
\end{tabular}

E

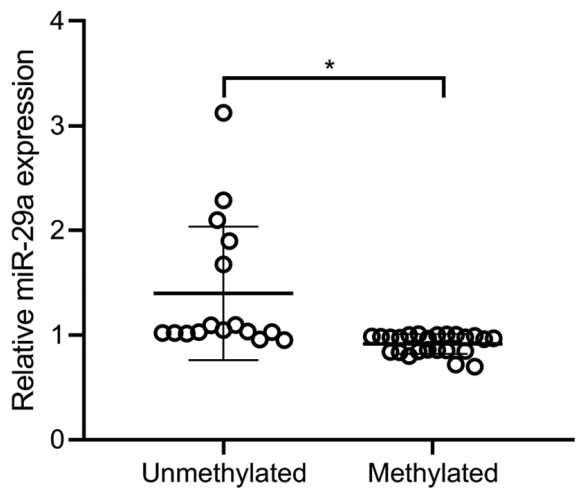

Figure 1. Correlation between miR-29a and p16 methylation in patients with cervical cancer. (A) Relative miR-29a expression in cervical cancer tissues and paired normal cervical tissues. (B) Relative miR-29a expression in cervical cancer cells (HeLa and C-33A) and the normal cervical cell line, ECT1/E6E7. (C) Representative images and the frequency of p16 methylation in cervical cancer tissues and normal tissues. (D) The methylation status of p16 promoter in cervical cells. (E) miR-29a expression in methylated and unmethylated p16 samples. Data are presented as the mean \pm standard deviation (n=3). " $\mathrm{P}<0.05$, ${ }^{* * *} \mathrm{P}<0.001$. miR, microRNA; NC, normal cervical tissues; $\mathrm{CC}$, cervical cancer tissues; T, cervical cancer; $\mathrm{N}$, normal control; U, unmethylated; M, methylated.

Statistical analysis. Statistical analysis was performed using SPSS v21.0 software (SPSS, Inc.) and the Prism statistical v8.0 software package (GraphPad Software, Inc.). All experiments were performed in triplicate and data are presented as the mean \pm standard deviation. Unpaired Student's t-test was used to compare differences between two groups, while one-way analysis of variance and Tukey's post hoc test were used to compare multiple groups. Pearson's correlation coefficient was used to assess linear correlation between miR-29a and DNMT3A or DNMT3B, and the correlation between p16 and DNMT3A or DNMT3B. P $<0.05$ was considered to indicate a statistically significant difference.

\section{Results}

miR-29a levels decrease in cervical cancer tissues and cells and are negatively correlated with p16 hypermethylation. RT-qPCR analysis was performed to detect miR-29a expression in 40 cervical cancer tissues and paired normal cervical tissues. The results demonstrated that miR-29a expression was significantly decreased in cervical cancer tissues compared with paired normal tissues ( $\mathrm{P}<0.001$; Fig. 1A). Consistently, miR-29a expression was lower in the cervical cancer cell lines (HeLa and C-33A) compared with the normal cervical cell line, ECT1/E6E7 ( $\mathrm{P}<0.001$; Fig. 1B). The methylation status of p16 promoter was assessed in 40 cervical cancer tissues and paracancerous tissues. As presented in Fig. 1C, hypermethylation of p16 occurred in $62.5 \%$ (25/40) of cervical cancer tissues and $15.0 \%$ (6/40) of paracancerous tissues. In addition, p16 was hypermethylated in HeLa and C-33A cells compared with ECT1/E6E7 cells (Fig. 1D). Notably, the levels of miR-29a in the unmethylated p16 group were higher than the methylated p16 group $(\mathrm{P}<0.05$; Fig. $1 \mathrm{E})$, suggesting that miR-29a may be associated with the methylation status of p16 in cervical cancer.

miR-29a suppresses cell proliferation and induces cell cycle arrest of HeLa and C-33A cells. To assess the biological 
A
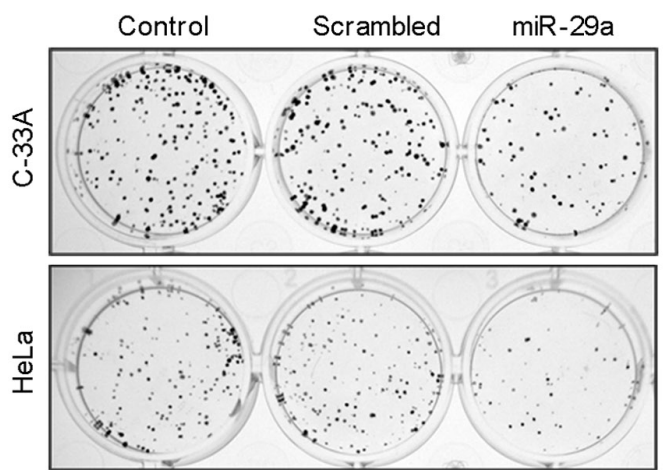

B
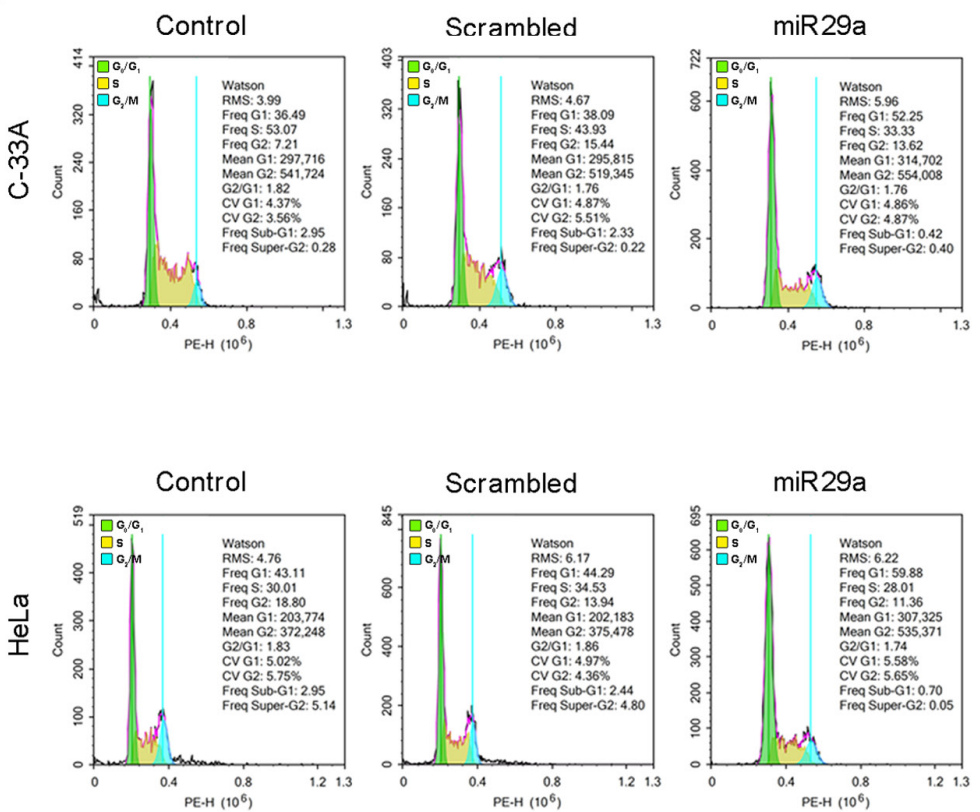
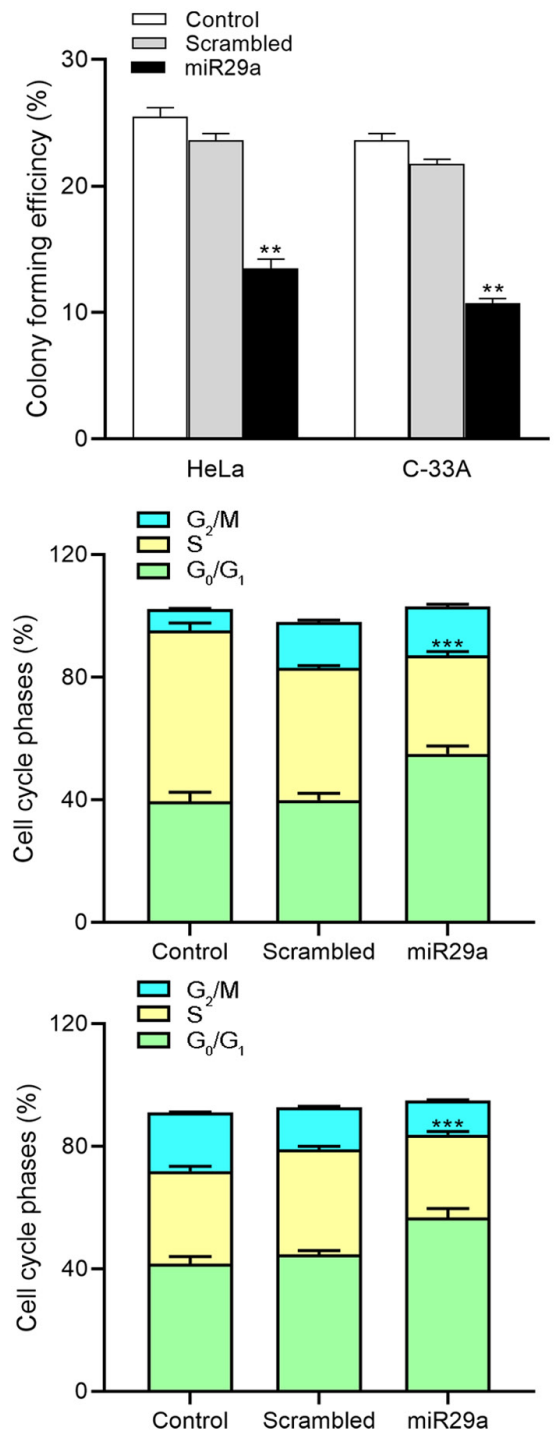

Figure 2. Ectopic miR-29a expression restrains cell proliferation and cell cycle of cervical cancer cells. (A) The colony formation efficiency decreased following overexpression of miR-29a in HeLa and C-33A cells. (B) Cell cycle analysis demonstrated that miR-29a induced cell cycle arrest at $\mathrm{G}_{0} / \mathrm{G}_{1}$ phase in HeLa and C-33A cells. Data are presented as the mean \pm standard deviation $(n=3) .{ }^{* *} \mathrm{P}<0.01,{ }^{* * * *} \mathrm{P}<0.001$ vs. control or scrambled group. miR, microRNA.

function of miR-29a in cervical cancer cell lines, HeLa and C-33A cells were transfected with miR-29a mimics or negative control, and subjected to the colony formation assay and cell cycle analysis. The results demonstrated that compared with the control groups, miR-29a mimics effectively increased the expression of miR-29a in HeLa and C-33A cells $(\mathrm{P}<0.001$; Fig. S1). Overexpression of miR-29a significantly decreased the colony formation capacity in both HeLa and C-33A cells compared with the negative control groups $(\mathrm{P}<0.01$; Fig. $2 \mathrm{~A})$. Furthermore, cell cycle analysis demonstrated that overexpression of miR-29a significantly promoted cell cycle arrest at $\mathrm{G}_{0} / \mathrm{G}_{1}$ phase in both HeLa and C-33A cells $(\mathrm{P}<0.001$; Fig. $2 \mathrm{~B})$. Taken together, these results suggest that miR-29a exerts an antitumor effect in cervical cancer cells.

miR-29ainhibitsDNMT3AandDNMT3Bexpressionbydirectly targeting their 3'-UTRs. To determine the association between miR-29a expression and p16 methylation status, DNMT3A and DNMT3B were selected as potential miR-29a targets for further experiments based on literatures and bioinformatics analysis. As predicted by the TargetScanHuman 7.2 database, miR-29a had intriguing complementarity sites in the 3'-UTRs of the DNMT3A and DNMT3B genes (Fig. 3A). To validate the interaction between miR-29a and targets, the 3'-UTRs of DNMT3A and DNMT3B were cloned into a modified pGL3 plasmid downstream of the luciferase reporter gene. Corresponding mutant versions with the binding site mutagenesis were also constructed, and subsequently co-transfected with miR-29a mimics in HeLa cell. The results demonstrated that miR-29a significantly decreased the luciferase activities in the wt-DNMT3A and wt-DNMT3B groups compared with the scrambled oligonucleotide $(\mathrm{P}<0.01$; Fig. $3 \mathrm{~B})$. miR-29a mimics was transfected into $\mathrm{HeLa}$ and $\mathrm{C}-33 \mathrm{~A}$ cells to assess whether miR-29a regulates DNMT3A and DNMT3B expression. As presented in Fig. 3C, transfection with miR-29a mimics significantly increased miR-29a expression in $\mathrm{HeLa}$ and $\mathrm{C}-33 \mathrm{~A}(\mathrm{P}<0.001)$. Furthermore, DNMT3A and DNMT3B expression in $\mathrm{HeLa}$ and $\mathrm{C}-33 \mathrm{~A}$ cells significantly decreased following overexpression of miR-29a ( $\mathrm{P}<0.01$; Fig. 3D). The association between DNMT3A or DNMT3B and miR-29a 
A

\begin{tabular}{|c|c|c|}
\hline Position 862-868 of DNMT3A 3' UTR & & ... AACCCGACUUCAUAAUGGUGCUU. wt \\
\hline & & 1111111 \\
\hline hsa-miR-29a & $3^{\prime}$ & AUUGGCUAAAGUCU-ACCACGAU \\
\hline & & $\star *|* * *|$ \\
\hline Position 862-868 of DNMT3A 3' UTR & $5^{\prime}$ & .... AACCCGACUUCAUAAUGGUGCUU... \\
\hline
\end{tabular}

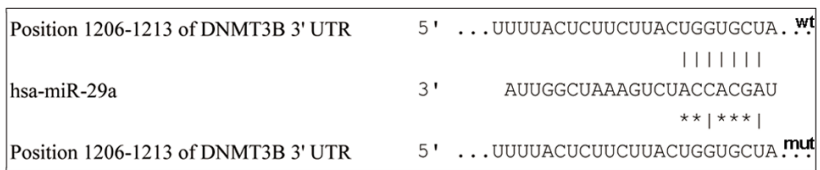
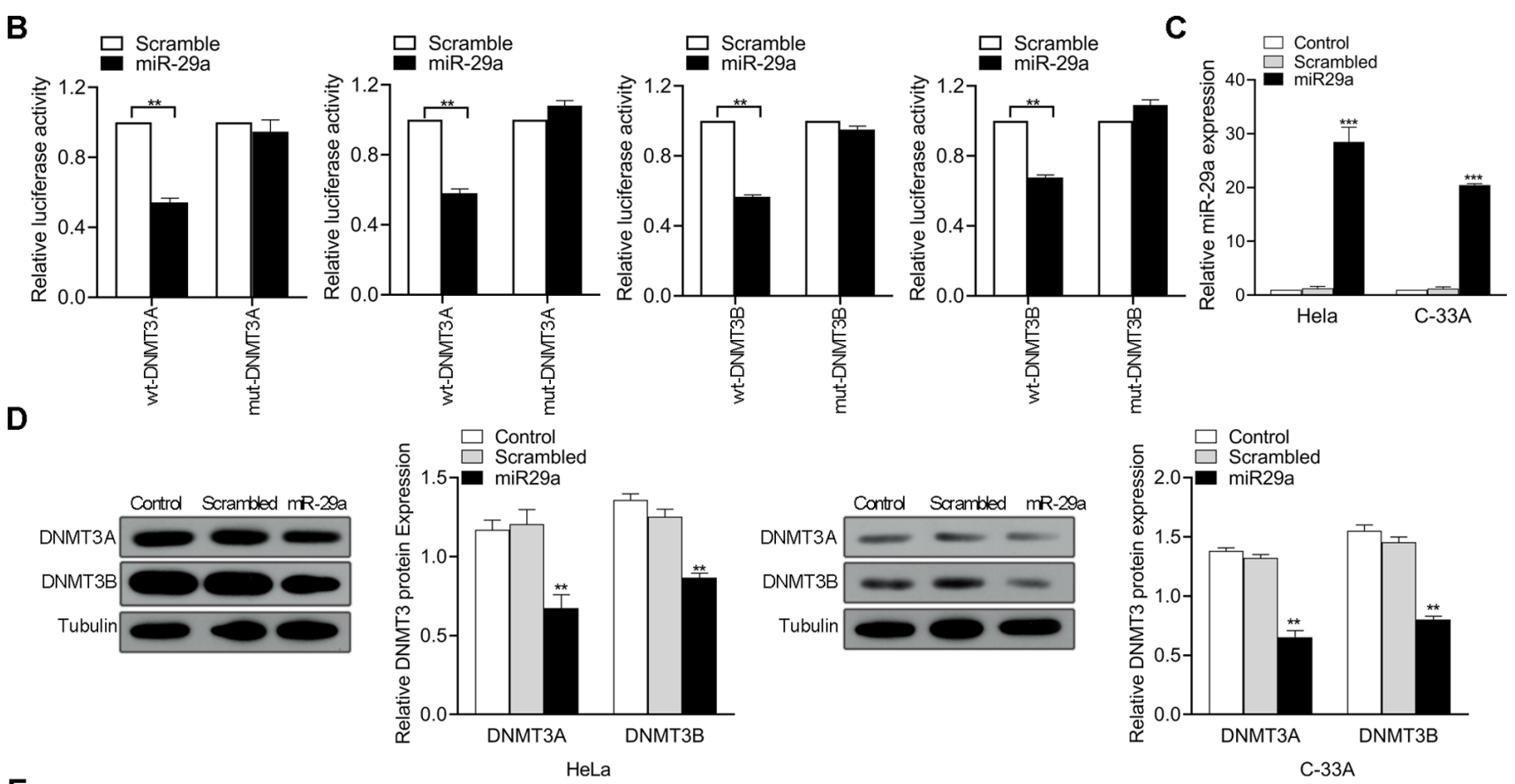

E
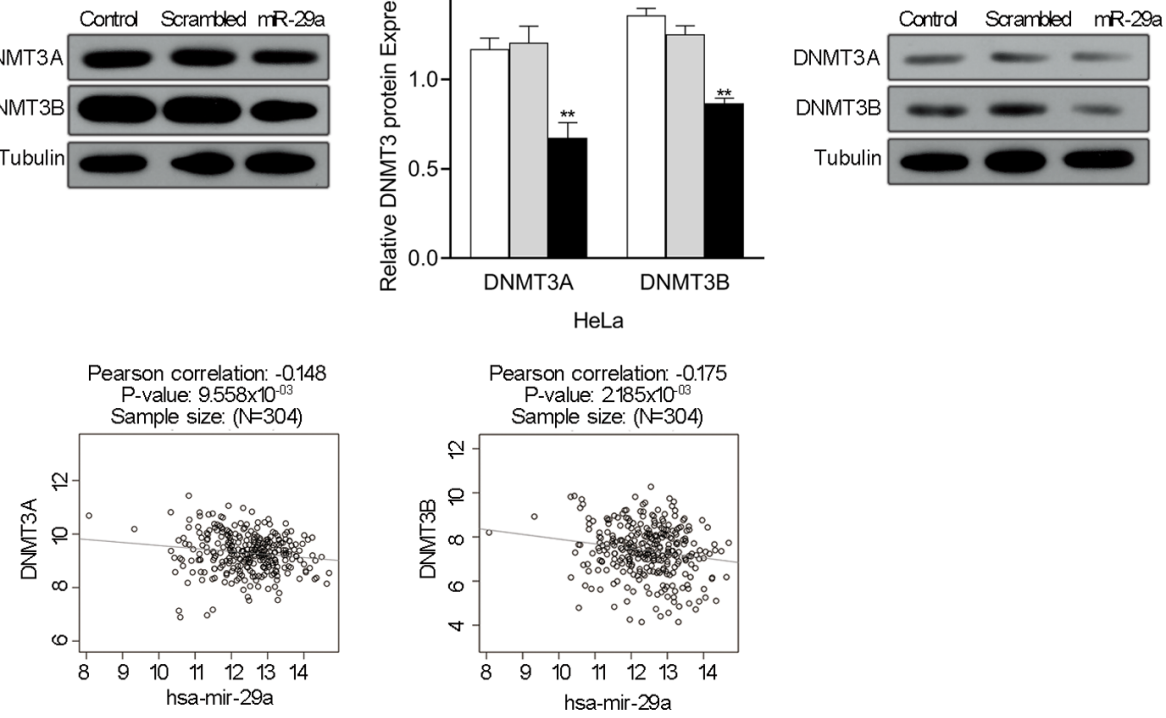

Figure 3. miR-29a directly targets DNMT3A and DNMT3B. (A) Complementarity sites for miR-29a in the 3'-UTR regions of DNMT3A and DNMT3B, according to the TargetScanHuman 7.2 database. (B) Results of the dual-luciferase reporter assay for DNMT3A and DNMT3B following transfection with miR-29a in HeLa and C-33A cells. (C) Reverse transcription-quantitative PCR analysis was performed to detect miR-29a expression in HeLa and C-33A cells transfected with miR-29a mimics or scrambled oligonucleotide. (D) Western blot analysis was performed to detect DNMT3A and DNMT3B protein expression levels in HeLa and C-33A cells following transfection with miR-29a or scrambled oligonucleotide. (E) Correlation between DNMT3A and DNMT3B mRNA levels and miR-29a expression in cervical cancer tissues analyzed using LinkedOmics. Data are presented as the mean \pm standard deviation $(\mathrm{n}=3)$. ${ }^{* *} \mathrm{P}<0.01$, ${ }_{* * * *} \mathrm{P}<0.001$ vs. control or scrambled group. ns, no significance; miR, microRNA; DNMT, DNA methyltransferase; UTR, untranslated; WT, wild-type; MUT, mutant.

expression levels in cervical cancer tissues was determined using LinkedOmics (http://www.linkedomics.org). Pearson's correlation analysis demonstrated that miR-29a expression was negatively correlated with DNMT3A and DNMT3B expression ( $\mathrm{P}<0.01$; Fig. 3E). Collectively, these results suggest that miR-29a decreases mRNA DNMT3A and DNMT3B expression by directly targeting to their 3'-UTRs.

miR-29a inhibits pl6 gene methylation via modulation of DNMT3A and DNMT3B. To assess the potential effect and molecular mechanism of miR-29a on the methylation pattern of p16 gene, HeLa and C-33A cells were transfected with miR-29a mimics, or siRNAs for DNMT3A and DNMT3B. The levels of DNMT3A and DNMT3B significantly decreased in cells transfected with their specific siRNAs compared with their corresponding control groups $(\mathrm{P}<0.001$; Fig. S2A and B). The MSP results demonstrated that miR-29a attenuated the methylation status of p16 in HeLa and C-33A cells (Fig. 4A). Furthermore, silencing of DNMT3A or DNMT3B, two key enzymes involved in DNA methylation (41), normalized aberrant methylation pattern of p16 in cervical cancer (Fig. 4B). In addition, LinkedOmics analysis demonstrated that p16 (also known as CDKN2A) mRNA expression was inversely correlated with DNMT3A or DNMT3B mRNA levels in cervical cancer tissues (P<0.001; Fig. 4C). Thus, miR-29a inhibits aberrant methylation of tumor suppressor gene p16 by regulating the levels of DNMT3A and DNMT3B. 
A
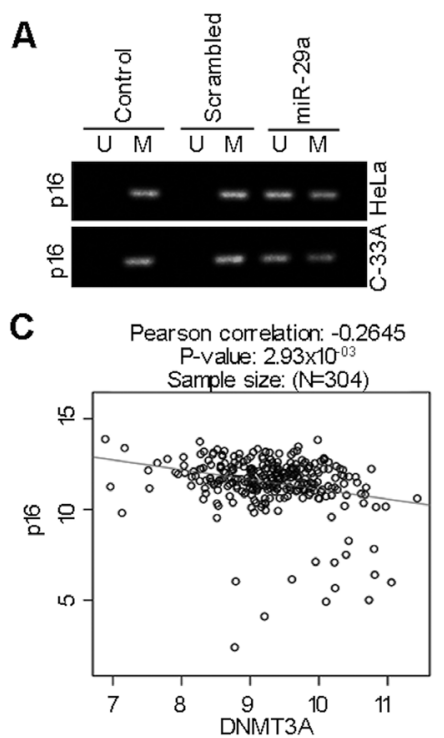

B
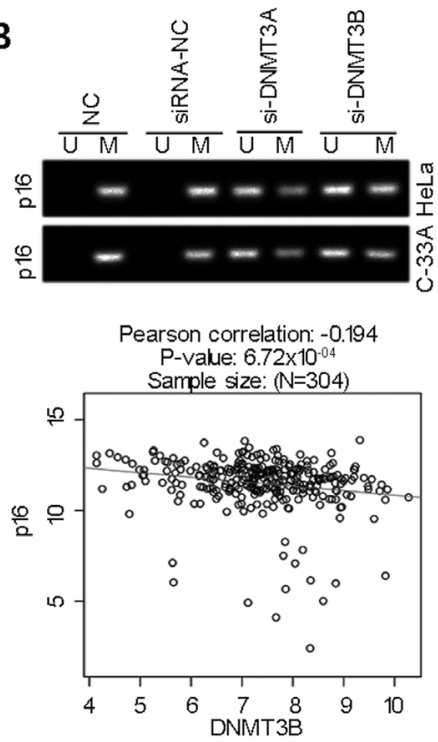

Figure 4. miR-29a inhibits p16 methylation by modulating DNMT3A and DNMT3B. (A) The methylation status of p16 following transfection with miR-29a mimics in HeLa and C-33A cells. (B) The methylation status of p16 following transfection with si-DNMT3A and si-DNMT3B in HeLa and C-33A cells. (C) Correlation between endogenous mRNA levels of DNMT3A and DNMT3B and levels of p16 in cervical cancer tissues analyzed using LinkedOmics. miR, microRNA; DNMT, DNA methyltransferase; si, small interfering; U, unmethylated; M, methylated; NC, negative control.

\section{Discussion}

miRNAs exhibit abnormal expression in different types of cancer, and exert tumor suppression or promotion effects by regulating the expression of target genes (42). For example, Chen et al (43) reported that miR-132 expression is significantly downregulated in thyroid cancer tissues and overexpression of miR-132 exerts tumor-suppressing functions through targeting FOXA1. Previous studies have demonstrated that miRNAs play a crucial regulatory role in cervical cancer. These studies contribute to a profound understanding of the molecular mechanism involved in the cervical cancer $(44,45)$. miR-29a has been reported to exert an antitumor effect in different types of cancer, and the disorder of miR-29a is associated with the development and progression of cancer (26).

The results of the present study demonstrated that miR-29a expression was downregulated in cervical cancer tissues and cell lines compared with normal cervical tissues and cells. In addition, overexpression of $\mathrm{miR}-29 \mathrm{a}$ inhibited the proliferation and induced cell cycle arrest in cervical cancer cells, which was similarly observed in previous studies. It has been demonstrated that miR-29a expression is downregulated in papillary thyroid cancer (46), oral squamous cell carcinoma (47), lung cancer (48) and retinoblastoma (48), as well as cervical cancer $(49,50)$, and ectopic miR-29a expression significantly inhibits proliferation and invasion. Taken together, these results confirm that miR-29a is a tumor suppressor (51).

The results of the present study demonstrated a significant correlation between miR-29a expression and methylation patterns of p16, and that overexpression of miR-29a normalized aberrant methylation status of the p16 gene. The p16 gene is a well-known tumor suppressor gene that blocks the $G_{1}-S$ phase of the cell cycle and inhibits abnormal proliferation of cancer cells (52). In addition, p16 protein inhibits the activation of cyclin-dependent kinase 4 and the phosphorylation of $\mathrm{pRb}$, and further blocks the cell cycle (10). Mutation, deletion and abnormal methylation of the p16 gene are frequently observed, which inactivates the p16 protein in different types of cancer and is closely associated with the development and progression of cancers $(53,54)$. Methylation of the p16 gene promoter inactivates p16, significantly decreasing its expression $(55,56)$. This results in the loss of the tumor suppressor function of p16, which promotes the development of cervical cancer (8). However, the regulatory mechanism of p16 promoter methylation remains unknown. Thus, to investigate the molecular mechanism by which miR-29a regulates the methylation status of p16 promoter, DNMT3A and DNMT3B were identified and confirmed as new direct targets for miR-29a via bioinformatics analysis and the dual-luciferase reporter assay. DNMT3A and DNMT3B are key DNA methyltransferases for de novo methylation, which are essential for the establishment of DNA methylation patterns during development (57). Abnormal expression of DNMTs and disruption of DNA methylation patterns are closely associated with the development of different tumors (58). Increasing evidence suggests that dysregulated DNMT3A and DNMT3B contributes to tumor progression by modulating the methylation of targets or the global DNA $(59,60)$. The present study demonstrated the associations between miR-29a, DNMT3A, DNMT3B and p16, and indicated that miR-19a suppressed cell proliferation and induced cell cell cycle arrest in cervical cancer cells by restoring DNMT-3s-induced methylation status of p16.

The results of the present study confirmed that miR-29a is involved in methylation modification of the tumor suppressor gene, p16, by directly targeting DNMT3s. The results demonstrated the underlying molecular mechanism by which miR-29a inhibits cell proliferation and arrests the cell cycle in cervical cancer. Taken together, these results provide a novel perspective for the biological significance of miR-29a in regulating methylation modification with potential diagnostic and therapeutic biomarkers for clinical cervical cancer management. 


\section{Acknowledgements}

Not applicable.

\section{Funding}

The present study was supported by the Qinghai Basic Research Program of China (grant no. 2018-0301-ZJC-0101).

\section{Availability of data and materials}

The datasets used and/or analyzed during the present study are available from the corresponding author upon reasonable request.

\section{Authors' contributions}

AW, QX and GG were involved in the study concept and design, analysis and interpretation of data and drafting the initial manuscript. RS, TB and XX were involved in the acquisition of data and analysis. All authors performed the experiments, revised and approved the final manuscript.

\section{Ethics approval and consent to participate}

The present study was approved by the Ethics Committee of the Affiliated Hospital of Qinghai University (Xining, China; approval no. SL-2018016), and written informed consent was provided by all patients prior to the study start.

\section{Patient consent for publication}

Not applicable.

\section{Competing interests}

The authors declare that they have no competing interests.

\section{References}

1. Freddie B, Ferlay J, Soerjomataram I, Siegel RL, Torre LA and Jemal A: Global cancer statistics 2018: GLOBOCAN estimates of incidence and mortality worldwide for 36 cancers in 185 countries. CA Cancer J Clin 68: 394-424, 2018.

2. Razavi ZS, Tajiknia V, Majidi S, Ghandali M, Mirzaei HR, Rahimian N, Hamblin MR and Mirzaei H: Gynecologic cancers and non-coding RNAs: Epigenetic regulators with emerging roles. Crit Rev Oncol Hematol 157: 103192, 2020.

3. Burd EM: Human papillomavirus and cervical cancer. Clin Microbiol Rev 16: 1-17, 2003.

4. Menezo Y, Clement P, Clement A and Elder K: Methylation: An ineluctable biochemical and physiological process essential to the transmission of life. Int J Mol Sci 21: 9311, 2020.

5. Zhu H, Zhu H, Tian M, Wang D, He J and Xu T: DNA methylation and hydroxymethylation in cervical cancer: Diagnosis, prognosis and treatment. Front Genet 9: 347, 2020.

6. Urbano A, Smith J, Weeks RJ and Chatterjee A: Gene-Specific targeting of DNA methylation in the mammalian genome. Cancers (Basel) 11: 1515, 2019.

7. Jiao Y, Feng Y and Wang X: Regulation of tumor suppressor gene CDKN2A and Encoded p16-INK4a protein by covalent modifications. Biochemistry (Mosc) 83: 1289-1298, 2018.

8. Wang FL, Yang Y, Liu ZY, Qin Y and Jin T: Correlation between methylation of the p16 promoter and cervical cancer incidence. Eur Rev Med Pharmacol Sci 21: 2351-2356, 2017.

9. O'Neill CJ and McCluggage WG: p16 expression in the female genital tract and its value in diagnosis. Adv Anat Pathol 13: 8-15, 2006.
10. Han YD, Wang XB, Cui NH, Zhang S, Wang C and Zheng F: Associations of P16INK4a promoter hypermethylation with squamous intra-epithelial lesion, cervical cancer and their clinicopathological features: A meta-analysis. Oncotarget 8: 1871-1883, 2017.

11. Kohler F and Rodríguez-Paredes M: DNA methylation in epidermal differentiation, aging, and cancer. J Invest Dermatol 140: 38-47, 2020.

12. Gujar H, Weisenberger DJ and Liang G: The roles of human DNA methyltransferases and their isoforms in shaping the epigenome. Genes (Basel) 10: 172, 2019.

13. Hassouna MM, Naguib M, Radwan EM, Abdel-Samiee M, Estaphan S and Abdelsameea E: DNA methyltransferases as potential biomarkers for HCV related hepatocellular carcinoma. Asian Pac J Cancer Prev 1: 3357-3363, 2020.

14. Zhu A, Hopkins KM, Friedman RA, Bernstock JD, Broustas CG and Lieberman HB: DNMT1 and DNMT3B regulate tumorigenicity of human prostate cancer cells by controlling RAD9 expression through targeted methylation. Carcinogenesis 11: bgaa088, 2020.

15. Cervena K, Siskova A, Buchler T, Vodicka P and Vymetalkova V: Methylation-based therapies for colorectal cancer. Cells 24: 1540,2020

16. Liu H, Song Y, Qiu H, Liu Y, Luo K, Yi Y, Jiang G, Lu M, Zhang Z, Yin J, et al: Downregulation of FOXO3a by DNMT1 promotes breast cancer stem cell properties and tumorigenesis. Cell Death Differ 27: 966-983, 2020.

17. Piyathilake CJ, Badiga S, Borak SG, Weragoda J, Bae S, Matthews R, Bell WC and Partridge EE: A higher degree of expression of DNA methyl transferase 1 in cervical cancer is associated with poor survival outcome. Int J Womens Health 9: 413-420, 2017.

18. Sundaram MK, Hussain A, Haque S, Raina R and Afroze N: Quercetin modifies $5^{\prime} \mathrm{CpG}$ promoter methylation and reactivates various tumor suppressor genes by modulating epigenetic marks in human cervical cancer cells. J Cell Biochem 120: 18357-18369, 2019.

19. Sundaram MK, Ansari MZ, Al Mutery A, Ashraf M, Nasab R, Rai S, Rais N and Hussain A: Genistein induces alterations of epigenetic modulatory signatures in human cervical cancer cells. Anticancer Agents Med Chem 18: 412-421, 2018.

20. Khan MA, Sundaram MK, Hamza A, Quraishi U, Gunasekera D, Ramesh L, Goala P, Al Alami U, Ansari MZ, Rizvi TA, et al: Sulforaphane reverses the expression of various tumor suppressor genes by targeting DNMT3B and HDAC1 in human cervical cancer cells. Evid Based Complement Alternat Med 2015: 412149, 2015.

21. Lu TX and Rothenberg ME: MicroRNA. J Allergy Clin Immunol 141: 1202-1207, 2018.

22. Kabekkodu SP, Shukla V, Varghese VK, D'Souza J, Chakrabarty S and Satyamoorthy K: Clustered miRNAs and their role in biological functions and diseases. Biol Rev Camb Philos Soc 93: 1955-1986, 2018.

23. Condrat CE, Thompson DC, Barbu MG, Bugnar OL, Boboc A, Cretoiu D, Suciu N, Cretoiu SM and Voinea SC: miRNAs as biomarkers in disease: Latest findings regarding their role in diagnosis and prognosis. Cells 9: 276, 2020.

24. Yang Y, Dodbele S, Park T, Glass R, Bhat K, Sulman EP, Zhang Y and Abounader R: MicroRNA-29a inhibits glioblastoma stem cells and tumor growth by regulating the PDGF pathway. J Neurooncol 145: 23-34, 2019.

25. Liu YB, Wang Y,Zhang MD, Yue W and Sun CN: MicroRNA-29a functions as a tumor suppressor through targeting STAT3 in laryngeal squamous cell carcinoma. Exp Mol Pathol 116: 104521, 2020.

26. Gong HL, Tao Y, Mao XZ, Song DY, You D and Ni JD: MicroRNA-29a suppresses the invasion and migration of osteosarcoma cells by regulating the SOCS1/NF- $\mathrm{KB}$ signalling pathway through negatively targeting DNMT3B. Int J Mol Med 44: 1219-1232, 2019.

27. Nan P, Niu Y, Wang $X$ and Li Q: miR-29a function as tumor suppressor in cervical cancer by targeting SIRT1 and predict patient prognosis. Onco Targets Ther 26: 6917-6925, 2019.

28. Zhang Y, Yang L, Wang S, Liu Z and Xiu M: miR-29a suppresses cell proliferation by targeting SIRT1 in hepatocellular carcinoma. Cancer Biomark 22: 151-159, 2018.

29. Liu ZJ, Chen SG, Yang YZ, Lu SJ, Zhao XM, Hu B and Zhang L: miR-29a inhibits adhesion, migration, and invasion of osteosarcoma cells by suppressing CDC42. Int J Clin Exp Pathol 12: 4171-4180, 2019. 
30. Chen $\mathrm{R}$ and Zhang L: miR-29a inhibits cell proliferation and migration by targeting the CDC42/PAK1 signaling pathway in cervical cancer. Anticancer Drugs 30: 579-587, 2019.

31. Shi C, Ren L, Sun C, Yu L, Bian X, Zhou X, Wen Y, Hua D, Zhao S, Luo W, et al: $\mathrm{miR}-29 \mathrm{a} / \mathrm{b} / \mathrm{c}$ function as invasion suppressors for gliomas by targeting CDC42 and predict the prognosis of patients. Br J Cancer 117: 1036-1047, 2017.

32. Zhang M, Guo W, Qian J and Wang B: Negative regulation of CDC42 expression and cell cycle progression by miR-29a in breast cancer. Open Med (Wars) 11: 78-82, 2016.

33. Yamamoto $\mathrm{N}$, Kinoshita $\mathrm{T}$, Nohata N, Yoshino $\mathrm{H}$, Itesako $\mathrm{T}$, Fujimura L, Mitsuhashi A, Usui H, Enokida H, Nakagawa M, et al: Tumor-suppressive microRNA-29a inhibits cancer cell migration and invasion via targeting HSP47 in cervical squamous cell carcinoma. Int J Oncol 43: 1855-1863, 2013.

34. Bibaki E, Tsitoura E, Vasarmidi E, Margaritopoulos G, Trachalaki A, Koutoulaki C, Georgopoulou T, Spandidos DA, Tzanakis N and Antoniou KM: miR-185 and miR-29a are similarly expressed in the bronchoalveolar lavage cells in IPF and lung cancer but common targets DNMT1 and COL1A1 show disease specific patterns. Mol Med Rep 17: 7105-7112, 2018.

35. Kogure T, Kondo Y, Kakazu E, Ninomiya M, Kimura O and Shimosegawa T: Involvement of miRNA-29a in epigenetic regulation of transforming growth factor-beta-induced epithelial-mesenchymal transition in hepatocellular carcinoma. Hepatol Res 44: 907-919, 2014.

36. Cicchini C, de Nonno V, Battistelli C, Cozzolino AM, De Santis Puzzonia M, Ciafrè SA, Brocker C, Gonzalez FJ, Amicone L and Tripodi M: Epigenetic control of EMT/MET dynamics: HNF4a impacts DNMT3s through miRs-29. Biochim Biophys Acta 1849: 919-929, 2015.

37. Robaina MC, Mazzoccoli L, Arruda VO, de Souza Reis FD, Apa AG, de Rezende LM and Klumb CE: Deregulation of DNMT1, DNMT3B and miR-29s in burkitt lymphoma suggests novel contribution for disease pathogenesis. Exp Mol Pathol 98: 200-207, 2015

38. Oliveira LH, Schiavinato JL, Fráguas MS, Lucena-Araujo AR, Haddad R, Araújo AG, Dalmazzo LF, Rego EM, Covas DT, Zago MA and Panepucci RA: Potential roles of microRNA-29a in the molecular pathophysiology of T-cell acute lymphoblastic leukemia. Cancer Sci 106: 1264-1277, 2015.

39. Zhou X, Zhao F, Wang ZN, Song YX, Chang H, Chiang Y and Xu HM: Altered expression of miR-152 and miR-148a in ovarian cancer is related to cell proliferation. Oncol Rep 27: 447-454, 2012.

40. Vasaikar SV, Straub P, Wang J and Zhang B: LinkedOmics: Analyzing multi-omics data within and across 32 cancer types. Nucleic Acids Res 46: D956-D963, 2018.

41. Gao L, Anteneh H and Song J: Dissect the DNMT3A- and DNMT3B-mediated DNA Co-methylation through a covalent complex approach. J Mol Biol 17: 569-575, 2020.

42. Di Leva G, Garofalo M and Croce CM: MicroRNAs in cancer. Annu Rev Pathol 9: 287-314, 2014

43. Chen X, Li M, Zhou H and Zhang L: miR-132 Targets FOXA1 and exerts tumor-suppressing functions in thyroid cancer. Oncol Res 29: 431-437, 2019.

44. Wang JY and Chen LJ: The role of miRNAs in the invasion and metastasis of cervical cancer. Biosci Rep 15: BSR20181377, 2019.

45. Li J, Liu Q, Clark LH, Qiu H, Bae-Jump VL and Zhou C: Deregulated miRNAs in human cervical cancer: Functional importance and potential clinical use. Future Oncol 13: 743-753, 2017.

46. Wang Y, Han J, Lv Y and Zhang G: miR-29a inhibits proliferation, invasion, and migration of papillary thyroid cancer by targeting DPP4. Onco Targets Ther 12: 4225-4233, 2019.
47. Huang C, Wang L, Song $\mathrm{H}$ and Wu C: miR-29a inhibits the progression of oral squamous cell carcinoma by targeting wnt $/ \beta$-catenin signalling pathway. Artif Cells Nanomed Biotechnol 47: 3037-3042, 2019.

48. Liu X, Lv X, Yang Q, Jin H, Zhou W and Fan Q: MicroRNA-29a functions as a tumor suppressor and increases cisplatin sensitivity by targeting NRAS in lung cancer. Technol Cancer Res Treat 17: 1533033818758905,2018

49. Li Y, Wang F, Xu J, Ye F, Shen Y, Zhou J, Lu W, Wan X, Ma D and Xie X: Progressive miRNA expression profiles in cervical carcinogenesis and identification of HPV-related target genes for miR-29. J Pathol 224: 484-495, 2011.

50. Zhu Y, Huang Y, Liu M, Yan Q, Zhao W, Yang P, Gao Q, Wei J, Zhao W and Ma L: Epigallocatechin gallate inhibits cell growth and regulates miRNA expression in cervical carcinoma cell lines infected with different high-risk human papillomavirus subtypes. Exp Ther Med 17: 1742-1748, 2019.

51. Gong Y, Wan JH, Zou W, Lian GY, Qin JL and Wang QM: miR-29a inhibits invasion and metastasis of cervical cancer via modulating methylation of tumor suppressor SOCS1. Future Oncol 15: 1729-1744, 2019.

52. Zhang CY, Bao W and Wang LH: Downregulation of p16(ink4a) inhibits cell proliferation and induces G1 cell cycle arrest in cervical cancer cells. Int J Mol Med 33: 1577-1585, 2014.

53. Suzuki N, Onda T, Yamamoto N, Katakura A, Mizoe Je and Shibahara T: Mutation of the p16/CDKN2 gene and loss of heterozygosity in malignant mucosal melanoma and adenoid cystic carcinoma of the head and neck. Int J Oncol 31: 1061-1067, 2007.

54. Aesif SW, Aubry MC, Yi ES, Kloft-Nelson SM, Jenkins SM, Spears GM, Greipp PT, Sukov WR and Roden AC: Loss of p16INK4A expression and homozygous CDKN2A deletion are associated with worse outcome and younger age in thymic carcinomas. J Thorac Oncol 12: 860-871, 2017.

55. Demokan S, Chuang A, Suoğlu Y, Ulusan M, Yalnız Z, Califano JA and Dalay N: Promoter methylation and loss of p16(INK4a) gene expression in head and neck cancer. Head Neck 34: 1470-1475, 2012

56. Allameh A, Moazeni-Roodi A, Harirchi I, Ravanshad M, Motiee-Langroudi M, Garajei A, Hamidavi A and Mesbah-Namin SA: Promoter DNA methylation and mRNA expression level of p16 gene in oral squamous cell carcinoma: Correlation with clinicopathological characteristics. Pathol Oncol Res 25: 1535-1543, 2019.

57. Zhang ZM, Lu R, Wang P, Yu Y, Chen D, Gao L, Liu S, Ji D, Rothbart SB, Wang Y, et al: Structural basis for DNMT3A-mediated de novo DNA methylation. Nature 554: 387-391, 2018.

58. Jin B and Robertson KD: DNA methyltransferases, DNA damage repair, and cancer. Adv Exp Med Biol 754: 3-29, 2013

59. Liu D, Wu K, Yang Y, Zhu D, Zhang C and Zhao S: Long noncoding RNA ADAMTS9-AS2 suppresses the progression of esophageal cancer by mediating $\mathrm{CDH} 3$ promoter methylation. Mol Carcinog 59: 32-44, 2020.

60. de Silanes IL, Gorospe M, Taniguchi H, Abdelmohsen K, Srikantan S, Alaminos M, Berdasco M, Urdinguio RG, Fraga MF, Jacinto FV and Esteller M: The RNA-binding protein HuR regulates DNA methylation through stabilization of DNMT3b mRNA. Nucleic Acids Res 37: 2658-2671, 2009.

This work is licensed under a Creative Commons Attribution-NonCommercial-NoDerivatives 4.0 International (CC BY-NC-ND 4.0) License. 